ULHOA, AB; PEREIRA, TNS; RIBEIRO, CSC; MOITA, AW; REIFSCHNEIDER, FJB. 2017. Obtenção e caracterização morfoagronômica de linhagens de pimenta do tipo Jalapeño Amarelo. Horticultura Brasileira 35: 343-348. DOI - http://dx.doi.org/10.1590/S0102-053620170305

\title{
Obtenção e caracterização morfoagronômica de linhagens de pimenta do tipo Jalapeño Amarelo
}

\author{
Arlysson B Ulhoa'; Telma NS Pereira'; Cláudia SC Ribeiroº ${ }^{2}$ Antonio W Moita ${ }^{2}$; Francisco JB Reifschneider ${ }^{2}$ \\ ${ }^{1}$ Universidade Estadual do Norte Fluminense (UENF), Campos dos Goytacazes-RJ; Brasil; arlyssonulhoa@gmail.com; telmasp2012@gmail. \\ com; ${ }^{2}$ Embrapa Hortaliças, Brasília-DF, Brasil; claudia.ribeiro@embrapa.br; antonio.moita@embrapa.br; francisco.reifschneider@embrapa.br
}

\section{RESUMO}

O gênero Capsicum, de grande importância mundial, ocorre tanto nos países tropicais como nos de clima temperado. De um total de 31 espécies, apenas cinco são consideradas domesticadas, as demais, semidomesticadas ou silvestres. Nos últimos anos, as pimentas passaram a ter maior demanda pelo mercado e, consequentemente, os trabalhos relacionados à caracterização, melhoramento e obtenção de novas cultivares receberam mais atenção dentro de instituições públicas de ensino e de pesquisa, assim como no setor privado. Este trabalho foi desenvolvido na Embrapa Hortaliças, com objetivo de caracterizar morfoagronomicamente linhagens de pimenta do tipo Jalapeño Amarelo, atividade essencial para o desenvolvimento de cultivares. Primeiramente foram identificadas três plantas segregantes da cultivar comercial do tipo Jalapeño Vermelho, que apresentaram frutos de coloração amarela. Com base nesse material, o trabalho foi desenvolvido em duas fases: na primeira, obtenção de linhagens homozigotas pelo método de Descendência de Uma Única Semente (do inglês Single Seed Descent); na segunda, caracterização das linhagens obtidas através de cinco descritores morfológicos de Capsicum propostos pelo IPGRI (1995) e posterior avaliação qualitativa das linhagens em campo, sendo usado o teste Scott-Knott para a análise estatística. Conclui-se que o método de melhoramento utilizado foi satisfatório, visto que, em 30 meses de trabalho, as linhagens avançaram cinco gerações $\left(\mathrm{S}_{5}\right)$. A caracterização morfológica e a avaliação qualitativa permitiram identificar diferenças significativas entre as linhagens. As linhagens promissoras identificadas neste trabalho foram CNPH 25.368, CNPH 25.373, CNPH 25.374, CNPH 25.375 e CNPH 25.377.

Palavras-chave: Capsicum annuиm var. annuиm, descritores, melhoramento genético, SSD.

\begin{abstract}
Development and morpho-agronomic characterization of Yellow Jalapeño pepper lines

The genus Capsicum, of great worldwide importance, is found in tropical as well as in temperate countries. Currently five species are considered domesticated, out of a total of 31, and the others are considered semi-domesticated or wild. In recent years, the market has demanded more peppers and, therefore, the work related to the characterization, breeding and development of new cultivars gained ground in public education and research institutions, as well as in the private sector. This work was developed at Embrapa Vegetables, Brasilia, Brazil and had as objective the development and morphoagronomic characterization of Yellow Jalapeño pepper lines. This work initiated with the identification of segregating plants in a Red Jalapeno cultivar, commercially available in Brazil, where three plants with yellow fruits were found. The work was developed in two phases: the first phase aimed to obtain homozygous inbred lines through SSD (Single Seed Descent); the second phase characterized the inbred lines obtained by using five morphological Capsicum descriptors proposed by IPGRI (1995) with subsequent qualitative field assessment of the inbreds, with the Scott-Knott test used for statistical analysis. It was possible to conclude that the breeding method used was satisfactory and $\mathrm{S}_{5}$ inbred lines were obtained in 30 months. Morphological characterization and qualitative evaluation have identified significant differences between inbreds. The promising inbreds identified in this study were CNPH 25.368, CNPH 25.373, CNPH 25.374, CNPH 25.375 and CNPH 25.377.
\end{abstract}

Keywords: Capsicum annuиm var. annuиm, descriptors, genetic improvement, SSD.

\section{(Recebido para publicação em 3 de junho de 2016; aceito em 8 de março de 2017) (Received on June 3, 2016; accepted on March 8, 2017)}

U m dos primeiros relatos com referência à caracterização de plantas de Capsicum foi feito por Dioszegi \& Fazekas (1807), no trabalho de Csillery (2006), que utilizou a nomenclatura proposta por Linnaeus para descrever C. annuum e C. sinense, esta última, mais tarde, denominada de C. chinense. A descrição e/ou caracterização de espécies é de extrema importância para sua identificação e diferenciação.

O Brasil é considerado um importante centro de diversidade de Capsicum (Lourenço et al., 1999). Bianchetti (1996) estima que o gênero Capsicum abranja entre 20 a 25 espécies e que o maior número dessas espécies (13) é encontrado no Brasil. Trabalhos de coleta desse gênero identificam a Bacia Amazônica como o centro de diversidade genética para algumas espécies. Para a correta identificação e o melhor conhecimento desse gênero, são necessárias não só a coleta, com o consequente enriquecimento dos Bancos de Germoplasma, mas também uma apropriada caracterização e avaliação dos acessos (Reifschneider, 2000).

O melhoramento genético de pimentas teve início com os primeiros agricultores que, ao selecionarem e preservarem tipos de pimentas que se 
mostravam mais atrativas e interessantes, estavam involuntariamente, praticando o método de melhoramento conhecido como seleção massal (Reifschneider, 2000). A seleção massal é muito comum no processo de domesticação de espécies, sendo as plantas menos produtivas e defeituosas eliminadas e as remanescentes, que apresentam as melhores características quanto à adaptabilidade e produtividade, mantidas (Allard, 1971).

O melhoramento de pimentas é similar àquele praticado para as outras solanáceas como o tomate, a berinjela e o pimentão, tendo em vista que a maioria dessas espécies é autógama. Os principais métodos de melhoramento usados no desenvolvimento de cultivares de pimenta são: Método Genealógico ou Pedigree, Método Descendente de Uma Única Semente [Single Seed Descent (SSD)], Retrocruzamento de Linhagens [do inglês "Inbred Backcross Line System" (IBLS)] e Retrocruzamento (Ribeiro \& Reifschneider, 2008a).

As pimentas têm sido usadas em programas de melhoramento de Capsicum como fontes de genes importantes, porém pouco explorado na forma mais cultivada, o pimentão (Pickersgill, 1997). No Brasil, existem poucas cultivares de pimenta protegidas no Ministério da Agricultura, Pecuária e Abastecimento (MAPA). Recentemente, a Embrapa Hortaliças iniciou dentro do seu programa de melhoramento de pimenta, o desenvolvimento de uma cultivar com frutos de cor amarela.

O objetivo desse trabalho foi obter e caracterizar morfologicamente as linhagens, em $\mathrm{S}_{5}$ do programa de melhoramento de Jalapeño Amarelo (Capsicum annuum var. annuum) da Embrapa Hortaliças, utilizando os descritores elaborados pelo Bioversity International, com o intuito de verificar aquelas que apresentam as melhores características, associando essa caracterização a avaliações agronômicas, para, posteriormente, serem selecionadas linhagens promissoras.

\section{MATERIAL E MÉTODOS}

Material genético - Foram identificadas três plantas segregantes num experimento de VCU (Valor de Cultivo e Uso), no campo experimental da Embrapa Hortaliças, na qual havia entre as testemunhas uma cultivar híbrida do tipo Jalapeño (Jalapeño Plus $\mathrm{F}_{1}$ ) da Agristar (Top Seed Premium), com frutos maduros de coloração vermelha. Verificou-se que esta cultivar estava segregando para cor de fruto no estádio maduro, nas cores vermelha e amarela. Três plantas com frutos amarelos foram identificadas e seus frutos colhidos individualmente. $\mathrm{O}$ desenvolvimento deste trabalho foi feito utilizando as plantas segregantes que apresentaram frutos de coloração amarela. Foi colhido um fruto de cada uma das plantas, e as sementes desses frutos foram extraídas e beneficiadas de acordo com a Regra de Análise de Sementes (MAPA, 2009). Posteriormente, foram catalogados no Banco de Melhoramento de Capsicum da Embrapa Hortaliças. A cultivar Jalapeño Plus $F_{1}$ se caracteriza por apresentar planta compacta, com excelente cobertura foliar, frutos com coloração vermelha, tamanho 10,2 x $3,5 \mathrm{~cm}$, uniformidade e ciclo de 125 dias. O fruto da planta 1 foi registrado como CNPH 25.000, o fruto da planta 2, como CNPH 25.001, e o fruto da planta 3, como CNPH 25.002. O fruto $\mathrm{CNPH}$ 25.000 deu origem a uma progênie de 17 indivíduos (CNPH 25.003 a CNPH 25.019); o CNPH 25.001, a 13 genótipos (CNPH 25.020 a CNPH 25.032); e o CNPH 25.002 deu origem a sete genótipos (CNPH 25.033 a CNPH 25.039), perfazendo um total de 37 genótipos.

Esses genótipos foram semeados em bandejas de poliestireno expandido com 72 células, com substrato Plantmax ${ }^{\circledR}$, mantidas em casa de vegetação (sementeira) com cobertura plástica. Após aproximadamente 25 dias, as plântulas foram transplantadas para vasos de $10 \mathrm{~L}$ e transportadas para casa de vegetação.

Nesta, os genótipos foram dispostos em fileiras duplas com espaçamento de $1,0 \mathrm{~m}$ entre fileiras e $0,7 \mathrm{~m}$ entre vasos. Foram adotados o sistema de irrigação por gotejamento e o manejo fitotécnico e sanitário recomendado para o cultivo de Capsicum (Ribeiro \& Reifschneider, 2008b).

Método de Melhoramento - As gerações foram avançadas seguindo a metodologia Single Seed Descent,
(SSD) ou Descendente de Uma Única Semente, com modificação (SSD-M). A modificação feita nesse trabalho foi alicerçada no uso de um fruto para o avanço da nova geração, e a cada nova geração eram semeadas cinco sementes, mas somente uma plântula era conduzida até a fase de maturação dos frutos, as demais eram desbastadas ainda na fase de plântula. Para a realização do método (SSD-M), os botões florais de cada genótipo foram protegidos por um copinho de papel alumínio antes da antese evitando que quando o estigma estivesse viável ele recebesse pólen de outros genótipos, impedindo, assim, a fecundação cruzada. Para garantir a autofecundação, foi também feita a polinização manual de botões, e com uma pinça, os grãos de pólen foram retirados das anteras (pré-antese) e, em seguida, depositados no estigma da mesma flor. Após esse procedimento, o botão floral polinizado foi protegido com um copinho de papel alumínio e no decorrer de 15 dias verificou-se a ocorrência de fertilização pela formação de fruto. Outro procedimento também utilizado foi a proteção das flores com gaiolas com telas antiafídicas, método utilizado em último caso, em que um galho da planta foi selecionado, feita a eliminação das flores já polinizadas ou frutos e colocada essa gaiola cobrindo esse galho e os frutos ali gerados, apresentaram menor possibilidade de polinização cruzada. Durante o avanço de gerações, foi feita a eliminação de plantas com frutos de coloração vermelha, visto ter ocorrido segregação para cor de fruto variando de amarelo a vermelho, tendo sido mantidos apenas os genótipos que apresentavam frutos de coloração amarela. Os genótipos foram autofecundados por cinco ciclos consecutivos e, pelas condições em que as plantas eram cultivadas, foi possível avançar cerca de duas gerações (autofecundação) por ano.

Condução do experimento - $\mathrm{O}$ experimento foi instalado de dezembro de 2012 a março de 2013, no campo experimental da Embrapa Hortaliças (15 55 58S, 48 $08 \mathrm{O}$, altitude $970 \mathrm{~m}$ ). Foram utilizadas 27 linhagens $\left(\mathrm{S}_{5}\right)$, além de duas testemunhas introduzidas para fins comparativos; uma se caracteriza por ser a genitora das linhagens de Ja- 
lapeño amarelo, CNPH 3836 ( Jalapeño Plus $\mathrm{F}_{1}$ ), e a outra foi a cultivar BRS Garça (C. annuum), desenvolvida pela Embrapa Hortaliças e protegida no SNPC. As linhagens avaliadas foram: CNPH 25.361, CNPH 25.368, CNPH 25.369, CNPH 25.370, CNPH 25.371, CNPH 25.372, CNPH 25.373, CNPH 25.374, CNPH 25.375, CNPH 25.376, CNPH 25.377, CNPH 25.378, CNPH 25.379, CNPH 25.380, CNPH 25.381, CNPH 25.382, CNPH 25.383, CNPH 25.384, CNPH 25.385, CNPH 25.386, CNPH 25.387, CNPH 25.388, CNPH 25.389, CNPH 25.390 e CNPH 25.391. Foram semeadas 30 sementes de cada linhagem em bandejas de poliestireno expandido com 72 células, com substrato Plantmax ${ }^{\circledR}$, mantidas em casa de vegetação (sementeira) com cobertura plástica. Após aproximadamente 45 dias, as plântulas foram transplantadas para o campo experimental. As parcelas foram compostas por cinco plantas, sendo a parcela útil do experimento constituída pelas três plantas centrais. $\mathrm{O}$ espaçamento utilizado foi de 1,0 m entre linhas e $0,5 \mathrm{~m}$ entre plantas. $\mathrm{O}$ delineamento experimental foi em blocos ao acaso, com três repetições. Durante o desenvolvimento das plantas, foram feitos os tratos culturais recomendados para a cultura. A condução do experimento foi feita de janeiro a abril, fora da época propícia ao cultivo de pimentas no Planalto Central, com objetivo de obter maior tempo hábil para a caracterização/ avaliação.

Descritores utilizados - Para a caracterização das linhagens foram considerados os cinco descritores mais discriminantes (IPGRI, 1995):

Produção de frutos por parcela (PF) - Soma da massa fresca de todos os frutos da parcela útil, mensurada por balança de precisão, em gramas.

Comprimento do fruto $(\mathrm{CF})$ - Mensurado no maior comprimento, em milímetros, quando o fruto estava maduro, utilizando paquímetro digital. Foram avaliados cinco frutos por parcela, totalizando 15 frutos, tomados ao acaso.

Largura basal do fruto (LBF) Mensurada na parte superior do fruto (após o pedúnculo), em milímetros, quando o fruto estava maduro, utilizando paquímetro digital. Foram avaliados cinco frutos por parcela, totalizando 15 frutos, tomados ao acaso.

Largura mediana do fruto (LMF) - Mensurada no meio do fruto, em milímetros, quando o fruto estava maduro, utilizando paquímetro digital. Foram avaliados cinco frutos por parcela, totalizando 15 frutos, tomados ao acaso.

Espessura de polpa do fruto (EPF) - Mensurada a partir de um corte transversal no meio do fruto, em milímetros, quando o fruto estava maduro, utilizando paquímetro digital. Foram avaliados cinco frutos por parcela, totalizando 15 frutos, tomados ao acaso.

Avaliação agronômica qualitativa preliminar - Adicionalmente, foi feita uma avaliação agronômica qualitativa preliminar, levando em consideração o porte da planta (verificado visualmente nas parcelas, classificado em alto ou baixo), a cor das folhas (verificado visualmente pela tonalidade das folhas das plantas, verde claro ou verde escuro) e a incidência de doenças (presença ou não de sintomas das doenças foliares). Esta avaliação foi feita por dois avaliadores independentes no final do ciclo (maio de 2013).

Análise estatística do experimento - Os dados obtidos no experimento foram analisados, utilizando o programa $\mathrm{R}$
(R Development Core Team, 2010), com o qual se fez a análise de variância e o agrupamento de médias de Scott-Knott, em nível de significância de $1 \%$.

\section{RESULTADOS E DISCUSSÃO}

A cada novo ciclo de avanço das gerações, os genótipos passaram por seleção visual e, gradativamente, o número de plantas com frutos vermelhos foi reduzindo (Figura 1). A partir da terceira geração $\left(\mathrm{S}_{3}\right)$, não houve mais surgimento de frutos vermelhos, apenas de frutos amarelos, e a população se estabilizou quanto à segregação na cor do fruto e isso provavelmente está associado ao nível de homozigose (cerca de 87,5\%) que as plantas atingiram nessa geração.

O método de melhoramento SSD-M possibilitou o avanço rápido das gerações de autofecundação dos genótipos. Em 30 meses de trabalho, foi possível obter cinco gerações de autofecundação $\left(\mathrm{S}_{5}\right)$ dos genótipos, devido ao avanço de gerações ter sido conduzido em casa de vegetação. O método foi considerado viável e simples porque é de fácil condução, com baixo requerimento de mão de obra uma vez que exclui sucessivas avaliações durante o avanço das gerações.

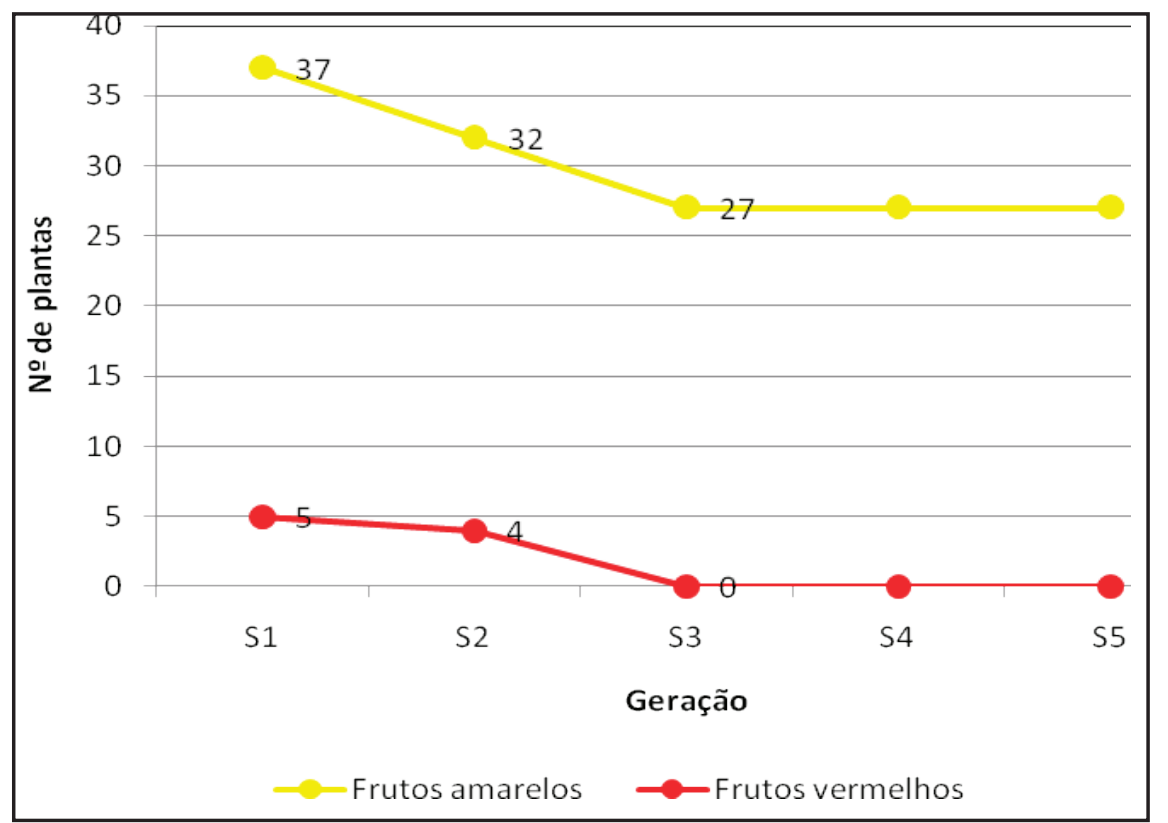

Figura 1. Número de plantas de Capsicum annuum var. annuum com frutos de cor amarela e vermelha, a cada geração de autofecundação (number of plants of Capsicum annuum var. annuит with yellow and red-colored fruits, on each generation of self-fertilization). Brasília, Embrapa, 2010. 
Tabela 1. Características avaliadas nas 28 linhagens de Jalapeño Amarelo (Capsicum annuum var. annuum), na geração $\mathrm{S}_{3}$. Média de cinco frutos e de três plantas \{characteristics evaluated in the 28 lines of Jalapeño Amarelo (Capsicum annuum var. annuum), in the $\mathrm{S}_{3}$ generation. Average of five fruits and three plants $\}$. Brasília, Embrapa, 2010.

\begin{tabular}{|c|c|c|c|c|c|}
\hline \multirow{3}{*}{ CNPH } & \multicolumn{4}{|c|}{ Frutos } & \multirow{3}{*}{$\begin{array}{c}\text { Altura da } \\
\text { planta } \\
(\mathrm{cm})\end{array}$} \\
\hline & \multirow{2}{*}{$\begin{array}{c}\text { Comprimento } \\
(\mathbf{m m})\end{array}$} & \multicolumn{2}{|c|}{ Largura (mm) } & \multirow{2}{*}{$\begin{array}{l}\text { Espessura de } \\
\text { polpa }(\mathrm{mm})\end{array}$} & \\
\hline & & Mediana & Basal & & \\
\hline 25.180 & 73 & 28 & 29 & 4,1 & 36 \\
\hline 25.181 & 71 & 24 & 26 & 3,7 & 31 \\
\hline 25.182 & 82 & 25 & 26 & 4,0 & 44 \\
\hline 25.183 & 67 & 23 & 26 & 3,6 & 33 \\
\hline 25.184 & 67 & 26 & 28 & 4,2 & 33 \\
\hline 25.185 & 70 & 24 & 26 & 3,4 & 34 \\
\hline 25.187 & 66 & 23 & 25 & 3,0 & 30 \\
\hline 25.188 & 72 & 27 & 29 & 3,8 & 40 \\
\hline 25.189 & 62 & 26 & 27 & 3,5 & 31 \\
\hline 25.190 & 75 & 25 & 28 & 4,0 & 28 \\
\hline 25.191 & 71 & 24 & 26 & 3,2 & 40 \\
\hline 25.192 & 74 & 26 & 29 & 4,6 & 40 \\
\hline 25.193 & 73 & 26 & 28 & 3,9 & 42 \\
\hline 25.194 & 77 & 22 & 24 & 3,4 & 25 \\
\hline 25.195 & 80 & 21 & 22 & 2,4 & 28 \\
\hline 25.196 & 92 & 18 & 19 & 2,3 & 39 \\
\hline 25.197 & 80 & 16 & 17 & 2,0 & 32 \\
\hline 25.198 & 85 & 21 & 21 & 2,2 & 26 \\
\hline 25.199 & 66 & 21 & 22 & 2,4 & 30 \\
\hline 25.200 & 91 & 24 & 24 & 3,2 & 44 \\
\hline 25.201 & 79 & 22 & 22 & 2,5 & 34 \\
\hline 25.202 & 76 & 21 & 21 & 2,8 & 28 \\
\hline 25.203 & 73 & 22 & 22 & 2,5 & 35 \\
\hline 25.204 & 80 & 27 & 29 & 3,9 & 24 \\
\hline 25.205 & 76 & 24 & 24 & 2,8 & 26 \\
\hline 25.206 & 83 & 27 & 26 & 4,0 & 30 \\
\hline 25.207 & 64 & 24 & 26 & 3,5 & 19 \\
\hline 25.208 & 96 & 26 & 27 & 4,3 & 24 \\
\hline BRS Garça & 96 & 28 & 26 & 3,4 & 65 \\
\hline
\end{tabular}

Considerando a escassez de mão de obra técnica nas instituições públicas e privadas e a baixa utilização deste recurso por este método quando comparado aos demais métodos de melhoramento, este método é mais indicado para programas de melhoramento de Capsicum baseados apenas em seleção.

A avaliação preliminar das linhagens na geração $\mathrm{S}_{3}$, Tabela 1 , possibilitou ganho de tempo com relação ao objetivo final do trabalho, visto terem sido eliminadas linhagens que não correspondiam ao desejado. De acordo com a caracterização realizada nas linhagens foi possível identificar algumas com potencial para atender à demanda do mercado, tais como: CNPH 25.196, que apresentou comprimento de fruto de 92 mm; CNPH 25.180, com largura mediana dos frutos de $28 \mathrm{~mm}$; CNPH 25.192, que se destacou pela largura basal do fruto $(29 \mathrm{~mm})$ e pela espessura de polpa (4,6 mm); e CNPH 25.182, que apresentou o maior valor para altura de planta, com $44 \mathrm{~cm}$, com potencial de cultivo em propriedades que utilizam colheita mecânica. Esses valores foram comparados a cultivar brasileira de frutos vermelhos BRS Garça, cujos valores médios são: comprimento do fruto de 96 $\mathrm{mm}$, diâmetro do fruto $28 \mathrm{~mm}$ e altura de planta $65 \mathrm{~cm}$.

Avaliação das linhagens $\mathrm{S}_{\mathbf{5}}$ - Pela utilização de descritores para caracterização, foi possível detectar variação entre as 24 linhagens avaliadas. Devido à implantação do experimento em época de alta precipitação (janeiro), dois genótipos (CNPH 25.380 e CNPH 3836) foram perdidos. Essas perdas foram ocasionadas pela alta incidência de doenças foliares, principalmente mancha bacteriana e antracnose. Houve diferença significativa $(\mathrm{P}<0,01)$ entre os tratamentos para os cinco descritores morfológicos produção de frutos por parcela, comprimento do fruto, largura basal do fruto, largura mediana do fruto e espessura de polpa do fruto. Silva et al. (2011) propuseram uma escala que divide os coeficientes de variação (CVs) obtidos para pimenta em quatro grupos (baixo, médio, alto e muito alto), para seis descritores morfológicos (peso médio do fruto, comprimento do pedúnculo, comprimento do fruto, maior e menor diâmetro do fruto e espessura do pericarpo). Segundo esse estudo, os CVs obtidos na presente pesquisa se enquadram em: muito alto $(\mathrm{CV}>29,59)$ para produção de frutos; médio $(8,23<\mathrm{CV} \geq 14,57)$ para comprimento do fruto; médio $(6,61<\mathrm{CV} \geq 11,63)$ para largura basal e mediana do fruto; e médio $(12,29<\mathrm{CV} \geq 24,73)$ para espessura de polpa do fruto. Sudré (2003), fazendo a caracterização agronômica de uma população de Capsicum spp. obteve valores de coeficiente de variação para comprimento do fruto $(8,55 \%)$, diâmetro do fruto $(6,93 \%)$ e peso de frutos por planta $(41,45 \%)$, próximo aos apresentados neste trabalho. Monteiro et al. (2010) constataram coeficiente de variação de $8,9 \%$ para largura de fruto. Moreira et al. (2010) apresentaram o coeficiente da variação para produção de 23\%; para diâmetro de fruto, o coeficiente de variação foi de 17,04\%. Sousa \& Maluf (2003) registraram um coeficiente de variação de $45,54 \%$ para produção total de fruto de pimenta; para comprimento de fruto e diâmetro de fruto, o coeficiente de variação foi 
Tabela 2. Avaliação de 24 linhagens de Jalapeño Amarelo (Capsicum annuum var. annuum) e uma testemunha comercial com relação a cinco descritores. Médias agrupadas pelo teste de Scott-Knott a $\mathrm{P}<0,01 \%$ \{evaluation of 24 Jalapeño Amarelo strains (Capsicum annuum var. annuиm) and one commercial control with respect to five descriptors. Averages grouped by Scott-Knott s test at $\mathrm{P}<0.01 \%$ \}. Brasília, Embrapa, 2010.

\begin{tabular}{|c|c|c|c|c|c|}
\hline \multirow[b]{2}{*}{ Genótipo } & \multirow[b]{2}{*}{$\begin{array}{l}\text { Produção } \\
\text { total (g) }\end{array}$} & \multicolumn{4}{|c|}{ Fruto } \\
\hline & & $\begin{array}{c}\text { Comprimento } \\
(\mathrm{mm})\end{array}$ & $\begin{array}{c}\text { Largura } \\
\text { basal (mm) }\end{array}$ & $\begin{array}{c}\text { Largura } \\
\text { mediana } \\
(\mathbf{m m})\end{array}$ & $\begin{array}{c}\text { Espessura } \\
(\mathrm{mm})\end{array}$ \\
\hline CNPH 25.368 & $1619,33 a$ & $63,8 b$ & $27,1 \mathrm{a}$ & $23,2 b$ & $2,9 b$ \\
\hline CNPH 25.361 & $1591,33 a$ & $71,7 \mathrm{~b}$ & $24,6 b$ & $23,3 b$ & $2,9 b$ \\
\hline CNPH 25.377 & $1268,00 \mathrm{a}$ & $65,9 b$ & $25,9 a$ & $22,7 b$ & $2,9 b$ \\
\hline CNPH 25.391 & $1238,67 \mathrm{a}$ & $67,8 b$ & $24,9 b$ & $24,5 \mathrm{a}$ & $3,2 \mathrm{a}$ \\
\hline CNPH 25.369 & $1221,33 a$ & $65,1 \mathrm{~b}$ & $29,2 \mathrm{a}$ & $25,0 \mathrm{a}$ & $4,0 \mathrm{a}$ \\
\hline CNPH 25.374 & $1135,33 a$ & $65,0 \mathrm{~b}$ & $27,7 \mathrm{a}$ & $23,9 a$ & $2,8 b$ \\
\hline CNPH 25.371 & $1009,33 a$ & $64,0 \mathrm{~b}$ & $29,1 \mathrm{a}$ & $25,5 \mathrm{a}$ & $3,7 \mathrm{a}$ \\
\hline CNPH 25.373 & $972,67 \mathrm{a}$ & $66,7 \mathrm{~b}$ & $27,5 \mathrm{a}$ & $23,0 \mathrm{~b}$ & $3,3 \mathrm{a}$ \\
\hline CNPH 25.389 & $901,00 \mathrm{a}$ & $64,6 \mathrm{~b}$ & $28,4 \mathrm{a}$ & $27,8 \mathrm{a}$ & $3,4 a$ \\
\hline CNPH 25.376 & $848,00 \mathrm{a}$ & $61,1 \mathrm{c}$ & $27,0 \mathrm{a}$ & $23,7 b$ & $3,3 \mathrm{a}$ \\
\hline CNPH 25.375 & $822,67 \mathrm{a}$ & $50,4 \mathrm{c}$ & $30,7 \mathrm{a}$ & $26,0 \mathrm{a}$ & $3,5 \mathrm{a}$ \\
\hline CNPH 25.390 & $674,00 \mathrm{~b}$ & $68,6 \mathrm{~b}$ & $22,7 b$ & $23,1 b$ & $2,7 \mathrm{~b}$ \\
\hline CNPH 25.379 & $639,00 \mathrm{~b}$ & $57,0 \mathrm{c}$ & $24,9 b$ & $21,9 b$ & $2,6 b$ \\
\hline CNPH 25.385 & $610,00 \mathrm{~b}$ & $77,1 \mathrm{~b}$ & $23,4 b$ & $22,2 b$ & $2,6 b$ \\
\hline CNPH 25.372 & $592,00 \mathrm{~b}$ & $59,6 \mathrm{c}$ & $26,7 \mathrm{a}$ & $22,4 b$ & $3,0 \mathrm{a}$ \\
\hline CNPH 25.378 & $586,67 \mathrm{~b}$ & $58,4 \mathrm{c}$ & $25,0 \mathrm{~b}$ & $22,3 b$ & $2,8 b$ \\
\hline CNPH 25.386 & $478,67 b$ & $71,3 b$ & $23,8 b$ & 24,3 & $2,7 b$ \\
\hline CNPH 25.383 & $452,00 \mathrm{~b}$ & $70,8 b$ & $21,7 \mathrm{c}$ & 20,9 & $2,2 \mathrm{~b}$ \\
\hline BRS Garça & $438,67 b$ & $96,8 \mathrm{a}$ & $27,9 a$ & 26,2 & $3,4 \mathrm{a}$ \\
\hline CNPH 25.370 & $414,00 \mathrm{~b}$ & $60,9 \mathrm{c}$ & $26,7 \mathrm{a}$ & 22,3 & $3,3 \mathrm{a}$ \\
\hline CNPH 25.384 & $258,00 \mathrm{~b}$ & $70,1 \mathrm{~b}$ & $26,7 \mathrm{a}$ & 25,3 & $2,8 b$ \\
\hline CNPH 25.381 & $238,67 b$ & $67,3 \mathrm{~b}$ & $20,0 \mathrm{c}$ & 19,5 & $1,9 b$ \\
\hline CNPH 25.382 & $189,67 b$ & $72,4 b$ & $19,5 \mathrm{c}$ & 18,8 & $1,9 b$ \\
\hline CNPH 25.388 & $176,33 b$ & $60,8 \mathrm{c}$ & $25,5 \mathrm{a}$ & 25,1 & $2,7 b$ \\
\hline CNPH 25.387 & $160,67 \mathrm{~b}$ & $68,7 \mathrm{~b}$ & $23,7 \mathrm{~b}$ & 23,1 & $2,2 \mathrm{~b}$ \\
\hline
\end{tabular}

de 8,05 e $12,06 \%$, respectivamente. As médias das linhagens para os cinco descritores foram agrupadas pelo teste de agrupamento de médias Scott-Knott (1974) (Tabela 2).

Características morfoagronômicas - 1) Produção total de frutos: as linhagens foram reunidas em dois grupos. O primeiro grupo foi composto por 11 linhagens. A linhagem que apresentou maior valor deste grupo foi a CNPH $25.368(1619,33 \mathrm{~g})$ e a que apresentou menor valor foi a $\mathrm{CNPH}$ $25.375(822,67 \mathrm{~g})$. O segundo grupo foi composto pela BRS Garça e por 13 linhagens. A linhagem que apresentou po foi a CNPH $25.385(77,1 \mathrm{~mm})$ e o menor valor foi encontrado na linhagem CNPH 25.368 (63,8 mm). O terceiro grupo foi composto pelas linhagens CNPH 25.370, CNPH 25.372, CNPH 25.375, CNPH 25.376, CNPH 25.378, CNPH 25.379 e CNPH 25.388. A linhagem que apresentou o maior valor desse grupo foi a CNPH $25.376(61,1 \mathrm{~mm}) \mathrm{e}$ o menor valor foi encontrado na linhagem CNPH 25.375 (50,4 mm). A BRS Garça apresenta comprimento de fruto de $96,8 \mathrm{~mm}$, e a linhagem com frutos mais compridos, a CNPH 25.385, teve frutos com 77,1 mm. 3) Largura basal do fruto: as linhagens foram agrupadas em três grupos. O primeiro grupo foi composto pela BRS Garça e por 13 linhagens. A linhagem que apresentou maior valor foi a CNPH 25.375, com $30,7 \mathrm{~mm}$. O segundo grupo foi composto por oito linhagens. Neste grupo, a linhagem que apresentou o maior valor foi a CNPH 25.378 (25 mm) e o menor valor foi encontrado na linhagem $\mathrm{CNPH}$ $25.390(22,7 \mathrm{~mm})$. O terceiro grupo foi composto por três linhagens, $\mathrm{CNPH}$ 25.381, CNPH 25.382 e CNPH 25.383, sendo os valores encontrados $20,0 \mathrm{~mm}$, $19,5 \mathrm{~mm}$ e $21,7 \mathrm{~mm}$, respectivamente. Moreira et al. (2010) trabalharam com 12 linhas endogâmicas de C. annuum e verificaram o diâmetro de fruto variando de 12,4 a $23,55 \mathrm{~mm}$. Segundo estes autores, em alguns híbridos há ocorrência de características comparáveis às das pimentas do tipo Jalapeño. Este resultado indica que as linhagens avaliadas apresentaram valores satisfatórios para essa característica. 4) Largura mediana do fruto: as linhagens foram agrupadas em três grupos. O primeiro grupo foi composto pela BRS Garça $(26,2 \mathrm{~mm})$ e por mais nove linhagens. A linhagem que apresentou o maior valor deste grupo foi a CNPH $25.389(27,8 \mathrm{~mm})$ e a que apresentou menor valor foi a CNPH $25.374(23,9 \mathrm{~mm})$. O segundo grupo foi composto por 12 linhagens. A linhagem que apresentou o maior valor deste grupo foi a CNPH $25.376(23,7$ $\mathrm{mm})$ e o menor valor foi encontrado na linhagem CNPH $25.379(21,9 \mathrm{~mm})$. $\mathrm{O}$ terceiro grupo foi composto por três linhagens. 5) Espessura de polpa: as linhagens foram reunidas em dois grupos. O primeiro grupo foi composto pela cultivar BRS Garça $(3,4 \mathrm{~mm})$ e por 
Tabela 3. Médias das cinco linhagens promissoras selecionadas, com os valores dos cinco descritores e respectivo agrupamento pelo método Scott-Knott (means of five selected lines with values of the five descriptors and the respective group by Scott-Knott). Brasília, Embrapa, 2010.

\begin{tabular}{lccccc}
\hline Linhagem & PF (g) & CF (mm) & LBF (mm) & LMF (mm) & EPF (mm) \\
\hline CNPH 25.368 & $1619,33 \mathrm{a}$ & $63,8 \mathrm{~b}$ & $27,1 \mathrm{a}$ & $23,2 \mathrm{~b}$ & $2,9 \mathrm{~b}$ \\
CNPH 25.373 & $972,670 \mathrm{a}$ & $66,7 \mathrm{~b}$ & $27,5 \mathrm{a}$ & $23,0 \mathrm{~b}$ & $3,3 \mathrm{a}$ \\
CNPH 25.374 & $1135,33 \mathrm{a}$ & $65,0 \mathrm{~b}$ & $27,7 \mathrm{a}$ & $23,9 \mathrm{a}$ & $2,8 \mathrm{~b}$ \\
CNPH 25.375 & $822,670 \mathrm{a}$ & $50,4 \mathrm{c}$ & $30,7 \mathrm{a}$ & $26,0 \mathrm{a}$ & $3,5 \mathrm{a}$ \\
CNPH 25.377 & $1268,00 \mathrm{a}$ & $65,9 \mathrm{~b}$ & $25,9 \mathrm{a}$ & $22,7 \mathrm{~b}$ & $2,9 \mathrm{~b}$ \\
\hline
\end{tabular}

$\mathrm{PF}=$ produção de frutos por parcela (fruit production per plot); $\mathrm{CF}=$ comprimento do fruto (lenght of fruit); $\mathrm{LBF}=$ largura basal do fruto (basal length of fruit); $\mathrm{LMF}=$ largura mediana do fruto (median fruit width); e EPF= espessura da polpa do fruto (pulp thickness of fruit).

mais nove linhagens. A linhagem que apresentou maior valor deste grupo foi a CNPH 25.369 (4 mm) e a que apresentou o menor valor foi a CNPH 25.372 (3 mm). O segundo grupo foi composto por 15 linhagens. Três linhagens (CNPH 25.361, CNPH 25.368 e CNPH 25.377) apresentaram o maior valor $(2,9 \mathrm{~mm})$ deste grupo e os menores valores foram encontrados em duas linhagens, com 1,9 $\mathrm{mm}$ de espessura de polpa (CNPH 25.381 e CNPH 25.382). A característica espessura de polpa é particularmente importante na produção de polpa usada na fabricação de molhos. A cultivar BRS Garça, genótipo de interesse da agroindústria, não diferiu estatisticamente das nove linhagens neste quesito.

Avaliação qualitativa - A linhagem CNPH 25.368 apresentou boa arquitetura de planta e alta produtividade. A linhagem CNPH 25.373, além de ser produtiva, também apresentou alta espessura de polpa, duas características essenciais para o desenvolvimento de uma cultivar para ser utilizada na produção de molho. A linhagem $\mathrm{CNPH}$ 25.374 possui fruto típico de pimenta Jalapeño, apresentando baixa incidência de mancha bacteriana. A linhagem CNPH 25.375 se destacou por apresentar frutos com maior largura basal (30,7 mm), cônicos e espessos, além de também apresentar baixa incidência de antracnose. Finalmente, a linhagem CNPH 25.377 apresentou alta uniformidade das plantas e não apresentou sintoma algum de mancha bacteriana e de antracnose.

Avaliação agronômica - Levando em consideração o resultado da caracterização morfoagronômica (Tabela 3) assim como os dados qualitativos preliminares obtidos pelos avaliadores independentes, foram identificadas cinco linhagens promissoras (CNPH 25.368, CNPH 25.373, CNPH 25.374, CNPH 25.375 e CNPH 25.377) por terem porte médio (que poderia eventualmente ser de utilidade quando da mecanização do cultivo), coloração verde escura da folhagem (desejável pela maior parte dos agricultores) assim como pela baixa incidência de doenças foliares, particularmente mancha bacteriana $\mathrm{e}$ antracnose, verificadas em campo.

Efetivamente, três das cinco linhagens identificadas passarão para a fase de produção de sementes genéticas e avaliação em campo no segundo semestre de 2013, possibilitando o desenvolvimento de uma nova cultivar.

\section{AGRADECIMENTOS}

Os autores agradecem à CAPES e ao $\mathrm{CNPq}$ pelo apoio para a realização deste trabalho.

\section{REFERÊNCIAS}

ALLARD, RW. 1971. Princípios do melhoramento genético das plantas. São Paulo: Edgard Blücher. 381p.

BIANCHETTI, LB. 1996. Aspectos morfológicos, ecológicos e biogeográficos de dez táxons de Capsicum (Solanaceae) ocorrentes no Brasil. Brasília: UnB, 176p. (Dissertação mestrado). CSILLÉRY, G. 2006. Pepper taxonomy and the botanical description of the species. Acta Agron Hungarica 54:151-166.

International Plant Genetic Resources Institute (IPGRI) 1995. Descriptors for Capsicum. International Plant Genetic Resources Institute, Rome.

LOURENÇO, RT; BIANCHETTI, LD; LINS, TCL; SILVA, NJML; BUSO, GCS; POZZOBON, M; FERREIRA, ME. 1999 New putative Capsicum species collected in the Brazilian Atlantic Forest and their genetic relationship with cultivated peppers: a first genetic view using molecular markers. In: Anais do Congresso Nacional de Genética, Resumos. Gramado: Sociedade Brasileira de Genética.

Ministério da Agricultura, Pecuária e Abastecimento (MAPA). 2009. Regras para análise de sementes. Ministério $d a$ Agricultura, Pecuária e Abastecimento MAPA. Brasília-DF. 31p.

MONTEIRO, ER; BASTOS, EM; LOPES, ACA; GOMES, RLF; NUNES, JAR. 2010. Diversidade genética entre acessos de espécies cultivadas de pimentas. Ciência Rural 40: 288-293.

MOREIRA, SO; RODRIGUES, R; ARAÚJO, ML; RIVA-SOUZA, EM; OLIVEIRA, RL. 2010. Desempenho agronômico de linhas endogâmicas recombinadas de Capsicum annuum L. em sistema orgânico sob cultivo protegido. Ciência e Agrotecnologia 34: 886-891.

PICKERSGILL, B. 1997. Genetic resources and breeding of Capsicum spp. Euphytica 96:129-133.

R Development Core Team 2010. R: A language and environment for statistical computing. R Foundation for Statistical Computing. Disponível em: http://www.R-project.org/

REIFSCHNEIDER, FJB. 2000. Capsicum pimentas e pimentões no Brasil. Embrapa, DF. Embrapa Comunicação para Transferência de Tecnologia. Embrapa Hortaliças. 113p.

RIBEIRO, CSC; REIFSCHNEIDER, FJB. 2008a. Genética e melhoramento. In: RIBEIRO, CSC; LOPES, CA; CARVALHO, SIC; HENZ, GP; REIFSCHNEIDER, FJB (org). Pimentas Capsicum. Brasília: Embrapa Hortaliças, p. 55-69.

RIBEIRO, CSC; REIFSCHNEIDER, FJB. 2008 b. Solos e adubação. In: ALCÂNTARA, FA; RIBEIRO, CSC. Pimentas Capsicum. Brasília: Embrapa Hortaliças, p. 81-93.

SILVA, AR; CECON, PR; RÊGO, ER; NASCIMENTO, M. 2011. Avaliação do coeficiente de variação experimental para caracteres de frutos de pimenteira. Ceres 58 : 168-171.

SOUSA, JA; MALUF, WR. 2003 Diallel analyses and estimation of genetic parameters of hot pepper (Capsicum chinense Jacq). Scientia Agricola 60: 105-113.

SUDRÉ, CP. 2003 Divergência genética e avaliação da resistência à mancha bacteriana em Capsicum ssp. Campos dos Goytacazes: UENF. 126p. (Dissertação mestrado). 